\title{
Natural and Synthetic Polymers as Inhibitors of Drug Efflux Pumps
}

\author{
Martin Werle ${ }^{1,2}$
}

Received April 4, 2007; accepted May 14, 2007; published online 26 September 2007

\begin{abstract}
Inhibition of efflux pumps is an emerging approach in cancer therapy and drug delivery. Since it has been discovered that polymeric pharmaceutical excipients such as Tweens ${ }^{\circledR}$ or Pluronics ${ }^{\circledR} \operatorname{can}$ inhibit efflux pumps, various other polymers have been investigated regarding their potential efflux pump inhibitory activity. Among them are polysaccharides, polyethylene glycols and derivatives, amphiphilic block copolymers, dendrimers and thiolated polymers. In the current review article, natural and synthetic polymers that are capable of inhibiting efflux pumps as well as their application in cancer therapy and drug delivery are discussed.
\end{abstract}

KEY WORDS: drug delivery; efflux pump inhibitors; P-glycoprotein; P-gp inhibitors; polymeric inhibitors.

\section{INTRODUCTION}

Since 1976, when Juliano and Ling identified a membrane glycoprotein to be responsible for drug resistance in colchicin drug resistant cells and designated it "P-glycoprotein," the interest of the scientific community in such transporters has been increasing from year to year (1). Various review articles addressing the localisation, mechanisms and nature of these transporters have been published previously $(2,3)$. Moreover, many review articles discuss the role of these transporter proteins in drug development and drug delivery (4-6). The $170 \mathrm{kDa}$ P-glycoprotein (P-gp), which is located in the apical membranes of epithelial cells, belongs to a group of transporter proteins that are known as efflux pumps. These ATP dependent transmembrane located transporter proteins can actively transport a wide range of structurally diverse compounds out of the cells; including anticancer agents (7), immunosuppressants (8), steroid hormones (9), calcium channel blockers (10), beta-adrenoreceptor blockers and cardiac glycosides $(11,12)$. They are over-expressed in cancer cells and are responsible for the multi drug resistance (MDR) of such cells. Besides, they are expressed in healthy tissues including liver, placenta, the proximal tubule in the kidney, capillary endothelial cells of brain and testis, and epithelial cells of the intestine $(2,3)$. In combination with other mechanisms, e.g., CYP3A, they act as a part of the detoxification system and affect absorption, distribution, metabolism and elimination (13). The encoding genes of these transporters belong to the ATP Binding Cassette (ABC) gene family. Apart from P-gp, other important efflux pumps are the multidrug resistant proteins (MRP) 1 and 2 as well as the breast cancer resistant protein (BCRP) (14).

\footnotetext{
${ }^{1}$ Department of Pharmaceutical Technology, Leopold-Franzens University Innsbruck, Innrain 52, 6020, Innsbruck, Austria.

${ }^{2}$ To whom correspondence should be addressed. (e-mail: martin. werle@uibk.ac.at)
}

Basically, an inhibition of efflux pumps can be applied to (a) improve the transport of efflux pump substrate anticancer agents into MDR cells and (b) drug delivery. The overexpression of efflux pumps such as $\mathrm{P}$-gp in tumours consequently leads to low concentrations of anticancer agents inside MDR cells during cancer therapy, so that therapeutic effects are minimized or do not occur at all. To circumvent MDR in cancer cells, researchers either focus on the development of novel therapeutic non-substrate agents or formulations that allow the drug to bypass efflux pump transport $(15,16)$, or on auxiliary agents that can inhibit efflux pumps (17). Regarding drug delivery, there are two main indications for efflux pump inhibition: oral delivery and blood brain barrier (BBB) delivery. The successful delivery of an orally administered drug to the systemic circulation is a very complex issue. Several strategies to overcome the barriers related to oral drug delivery including the use of solubility enhancers (18), permeation enhancers (19), enzyme inhibitors (20), mucoadhesive drug delivery systems or microand nanoparticulate drug delivery systems have been investigated and are still of enormous interest for pharmaceutical technologists $(21,22)$. In recent years, it has been demonstrated that improved oral bioavailability of efflux pump substrates can be achieved by co-administration of efflux pump inhibitors $(23,24)$. Another interesting application of efflux pump inhibitors combining oral drug delivery and cancer therapy might be the local treatment of gastrointestinal carcinoma. The $\mathrm{BBB}$ significantly restricts the delivery of certain drugs to the brain. Besides the brain microvessel endothelial cells, that form tight extracellular junctions and have low pinocytic activity, efflux transporters that remove drugs from the epithelial cells are responsible for the limited transport (25). An improved transport of efflux pump substrates over the blood brain barrier can be achieved by inhibiting BBB located efflux pumps (26).

In general, efflux pump inhibitors can be divided in small molecule inhibitors (SMIs) and polymeric inhibitors. 
First generation SMIs are pharmacological active compounds such as quinine or verapamil that are used in other clinical indications and which were found to additionally inhibit efflux pumps $(27,28)$. Second and third generation SMIs such as PSC833, GF120918 or KR30031 have been developed to exclusively inhibit efflux pumps and to avoid further pharmacological interactions $(23,29,30)$. However, co-administration of SMIs commonly bears the risk of SMI mediated toxicity, accumulation or anti-targeting. In recent years, some widely used safe and so far believed pharmacological inactive polymeric pharmaceutical excipients including Tween ${ }^{\circledR} 80$ and pluronic ${ }^{\circledR}$ P85 have been identified to inhibit efflux pumps $(31,32)$. The beneficial effect of such polymers in cancer therapy and drug delivery has been demonstrated by various in vitro and in vivo studies. Regarding polymer source, it can be distinguished between natural and synthetic polymers. Within the current review, so far investigated polymeric efflux pumps inhibitors and their use in cancer therapy as well as in drug delivery will be discussed.

\section{NATURAL POLYMERIC EFFLUX PUMP INHIBITORS}

Various efflux pump inhibitory compounds occur in nature. It has been demonstrated for example that polyphenols of green tea and compounds of grapefruit juice can inhibit efflux pumps $(33,34)$. Naturally occurring polymers include polysaccharides, polypeptides and proteins. Polysaccharides are the most frequently used group of natural polymers in pharmaceutical compositions. Among them are polymers such as starch, cellulose, hyaluronic acid and the chitin derived chitosan. Although extensive literature review has been performed, not much evidence for an efflux pump inhibitory activity of any of these polymers could be found. However, there is data available that supports the hypothesis that polysaccharides can inhibit efflux pumps. CarrenoGomez and Duncan filed a patent, which covers the use of polysaccharides, surfactants and dendrimers as efflux pump inhibitors for the oral delivery of antitumor, antineoplastic, antibiotic, antiviral, antifungal and antidepressant drugs. Polysaccharides comprising D-mannosyluronic acid, L-gulosyluric acid, D-glucose and/or D-glucuronic acid as well as D-mamose, D-mannuronic acid and/or D-mannose monomers are protected by the invention. Furthermore, the patent includes all polysaccharides comprising the monomers listed above with carboxylic groups. Experimental data that proofs the efficacy of dextran, anionic gums as well as sodium alginates to inhibit efflux pumps is provided within the patent (35).

\section{Anionic Gums}

Representatives of natural gum polysaccharides include agar, gellan gum, gum arabic, gum traganth, guar gum, carrageenan and xanthan. Xanthan gum and gellan gum are both used as food additives. Xanthan gum is produced by a process involving fermentation of glucose or sucrose by the Xanthomonas campestris bacterium. Gellan gum is produced by the bacterium Sphingomonas elodea. The structures of xanthan gum and gellan gum are presented in Fig. 1. The effect of $0.5 \mathrm{mg} / \mathrm{ml}$ xanthan gum was evaluated with the everted gut sac method and it was shown that in the presence of xanthan gum the accumulation of the P-gp substrates $\mathbf{a}$

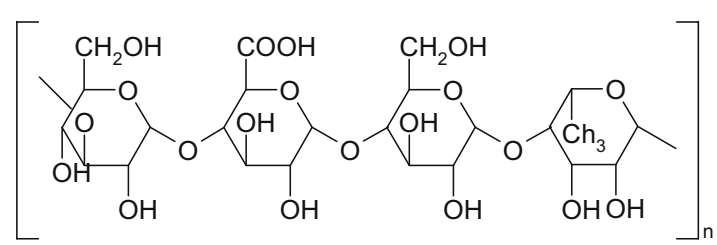

b

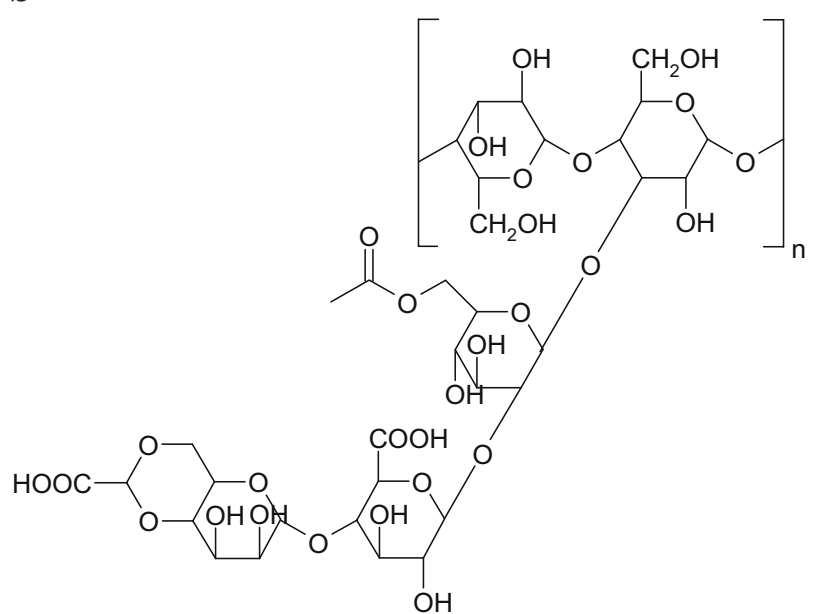

Fig. 1. Chemical structure of anionic gums: a gellan gum, b xanthan gum

vinblastin and doxorubicin in the gut cells was increased. An enhanced serosal transport of vinblastin but not of doxorubicin was observed (35). Also the potential efflux pump inhibitory activity of gellan gum was investigated. It could be demonstrated that at a concentration of $0.5 \mathrm{mg} / \mathrm{ml}$ gellan gum the serosal transport of vinblastin was improved, whereas the tissue level remained unchanged. At the same concentration, gellan gum improved the accumulation and the serosal transport of doxorubicin (35).

\section{Sodium Alginate}

Alginates are linear copolymers with blocks of (1-4)linked $\beta$-D-mannuronate $(\mathrm{M})$ and $\alpha$-L-guluronate $(\mathrm{G})$. The monomers can appear in consecutive G-residues (G-blocks), consecutive M-residues (M-blocks), alternating $\mathrm{M}$ and $\mathrm{G}$ residues (MG-blocks) or randomly organized blocks (Fig. 2). Representatives which have been evaluated regarding efflux pump inhibition are flavicam and ascophyllum. Flavicam is gained from Lessonia flavicams. In studies with everted gut sac cells, $0.5 \mathrm{mg} / \mathrm{ml}$ flavicam increased the accumulation of doxorubicin in the cells as well as the serosal transport of the drug, whereas no effect on vinblastin accumulation could be observed (35). Ascophyllum is extracted from Ascophyllum nodosum. Ascophyllum, at a concentration of $0.5 \mathrm{mg} / \mathrm{ml}$, increased vinblastin and doxorubicin accumulation in everted gut sac cells. Furthermore the serosal transport of vinblastin was enhanced, whereas the serosal transport of doxorubicin could not be improved. Moreover, the effect of $250 \mathrm{mg} / \mathrm{kg}$ ascophyllum on the biodistribution of radioactive labelled vinblastin after oral gavage in rats was investigated. The vinblastin blood level increased 1.7-fold in comparison to the control (35). Besides the discussed polysaccharides, also 
МMM

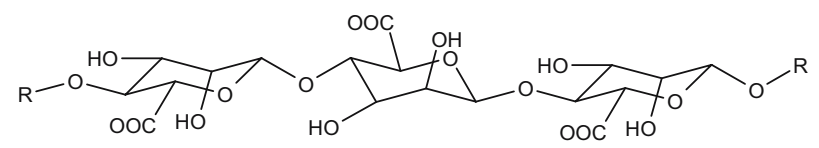

GGG

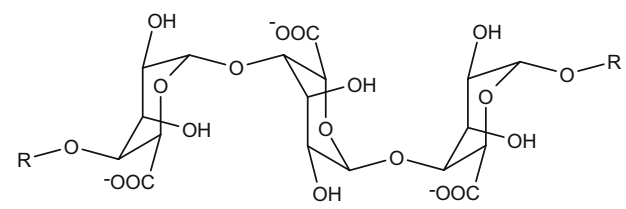

MGM

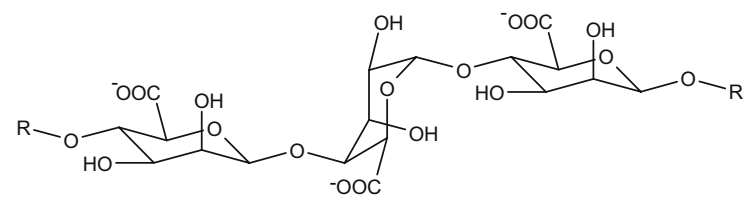

Fig. 2. Chemical structure of alginates; consecutive M-residues $(M M M)$, consecutive G-residues $(G G G)$, alternating $\mathrm{M}$ and $\mathrm{G}$ residues $(M G M)$

dextran showed efflux pump modifying effects, depending on the concentrations used (35).

\section{SYNTHETIC POLYMERIC EFFLUX PUMP INHIBITORS}

A broad variety of synthetic polymers are used in pharmaceutical applications. Historically, they have been used as auxiliary agents in formulations where any pharmacological effect of the auxiliary agent is undesirable. However, nowadays some interactions of such polymers with (patho)physiological processes are known to contribute to an improved action of the drug formulation. Naturally derived polymers such as chitosan can, for example, improve drug permeation through biological membranes via an opening of tight junctions. Synthetic polymers based on such polymeric backbones often exhibit improved features (36). Besides modifications of natural polymers, novel polymers can be synthesised via polymerization of monomers. Synthetic polymers used in pharmaceutical applications can also be produced via coupling of a synthetic polymer such as polyethylene glycol (PEG) to naturally occurring substances such as fatty acids. It has been shown previously, that various widely used synthetic polymeric pharmaceutical agents can inhibit efflux pumps. Among them are polyethylene glycols and PEG based detergents, copolymers such as poloxamers, dendritic polymers and thiolated polymers.

\section{Polyethylene Glycol}

Polyethylene glycols [PEG; a.k.a. polyethylene oxide (PEO) glycol and polyoxyethylene (POE) glycol] are polymers produced via polymerization of ethylene oxide molecules. Depending on their molecular weight, PEGs are liquids or low-melting solids. Johnson et al. showed that concentrations of 1-20\% of PEG 400 significantly decreased the basolateral to apical transport of digoxin through stripped rat jejunal mucosa, indicating efflux pump inhibition (37). Shen et al. investigated the potential of PEG 400, 2000 and 20,000 regarding efflux pump inhibition. They showed in experiments with diffusion chambers and isolated rat intestine that the secretory transport of rhodamine 123 was inhibited by the addition of different concentrations (0.1$20 \% v / v$ or $w / v)$ of PEGs, irrespective of their molecular weight (38). Additionally, they demonstrated in in situ closed loop studies, that the absorption of rhodamine 123 was improved when formulated in solutions containing different concentrations of PEG 20,000. It could be demonstrated by Hugger et al., that the permeation of efflux pump substrates such as doxorubicin and paclitaxel through Caco-2 monolayers was improved in the presence of PEG 300. A concentration dependent effect of PEG 300 on paclitaxel transport was observed. Apical to basolateral transport increased by using increasing concentrations of PEG 300, whereas basolateral to apical transport decreased accordingly. It was concluded that the efflux pump inhibition mechanism of PEG 300 was mediated by changes in the microenvironment of Caco-2 cell membranes (39). These changes are probably related to modifications in the fluidity of the polar head group regions of cell membranes. Furthermore, the same research group investigated the potential of PEG 300 in MDR1 transfected Madin Darby Canine Kidney (MDR1-MDCK) cell lines. PEG 300 (20\%, v/v) caused almost complete P-gp inhibition in Caco-2 and MDR1MDCK cells, whereas Cremophor ${ }^{\circledR}$ EL $(0.1 \%, w / v)$ and Tween ${ }^{\circledR} 80(0.05 \%, w / v)$ only partially inhibited P-gp activity in Caco-2 cells and turned out to be inactive as P-gp inhibitors in MDR1-MDCK cell monolayers (40). Furthermore, an increased uptake of PEGylated paclitaxel in comparison to unmodified paclitaxel after oral administration was observed. It was concluded that the water soluble PEGylated prodrug was able to partly bypass P-glycoprotein efflux and CYP3A metabolism, which might explain the significantly improved absorption (41).

\section{PEG Based Detergents}

It has been demonstrated that various polymeric surfactants including D-alpha-tocopheryl poly(ethylene glycol) succinate 1000 , polysorbates as well as POE stearates and alkyl-PEO surfactants are capable of inhibiting efflux pumps. Although only parts of their chemical structure have polymeric character and their molecular mass is typically below 2,000 $\mathrm{Da}$, the most important representatives are introduced below. Exemplarily, the structures of Tween ${ }^{\circledR}$ 80 and TPGS 1000 are shown in Fig. 3.

\section{D-Alpha-Tocopheryl Poly(ethylene glycol) Succinate 1000}

This compound has been used as a solubilising agent, an emulsifier and in lipid based drug delivery. TPGS 1000 is comprised of a hydrophilic head and a lipophilic alkyl tail. Varma and Panchnagula recently demonstrated that TPGS 1000 can improve the oral bioavailability of the BCS class IV drug and P-gp substrate paclitaxel and that this effect is mediated by an improved drug solubility and P-glycoprotein inhibition. A formulation containing $25 \mathrm{mg} / \mathrm{kg}$ paclitaxel and $50 \mathrm{mg} / \mathrm{kg}$ TPGS 1000 improved the oral bioavailability in rats 
Tween 80

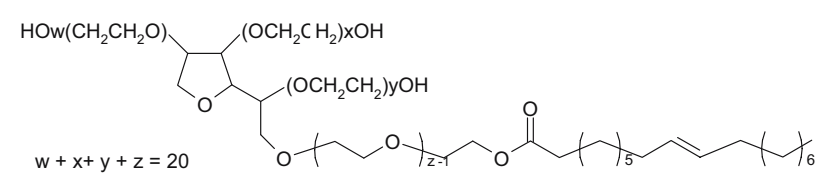

TPGS 1000

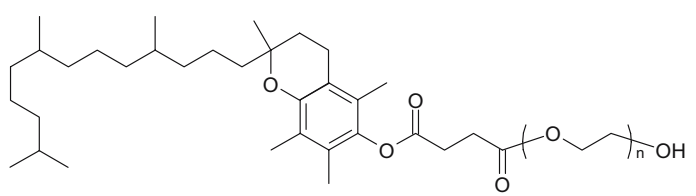

Fig. 3. Chemical structures of Tween ${ }^{\circledR} 80$ and TPGS 1000

about sixfold, leading to an oral bioavailability of about $30 \%$ (18). The paclitaxel plasma levels after oral administration of the TPGS 1000 formulation in comparison to paclitaxel alone are shown in Fig. 4. To gain more information regarding the mechanism of TPGS 1000 mediated efflux pump inhibition, the research group of Lehr investigated the influence of the length of the alkyl-chain of various TPGS derivatives on their efflux pump inhibitory activity. Results of ten different TPGS derivatives ranging from TPGS 200-6000 revealed that the commercially available derivative TPGS 1000 is the so far most potent efflux pump inhibitor. However, according to a Weinbull-distribution, promising TPGS derivatives may be found in the range between TPGS 1100 and TPGS 1500 (42).

\section{Polysorbates}

Polysorbates are PEGylated sorbitanes esterified with fatty acid. They are usually known under the brand name Tween ${ }^{\circledR}$. Most important regarding efflux pump inhibition are polyoxyethylene sorbitan monolaurates (Tween ${ }^{\circledR} 20$ ), polyoxyethylene sorbitan monopalmitates (Tween $\left.{ }^{\circledR} 40\right)$ and polyoxyethylene sorbitan monooleates (Tween ${ }^{\circledR}$ 80). Various studies demonstrate the ability of Tweens ${ }^{\circledR}$ to inhibit efflux pumps. In 1990, Friche et al. observed an increased accumulation of daunorubicin in resistant Ehrlich ascites tumor cells in the presence of $0.01 \%(v / v)$ Tween ${ }^{\circledR} 80(31)$. In another study, the efflux ratio (basolateral to apical drug transport/ apical to basolateral drug transport) was reduced in the presence of Tween ${ }^{\circledR} 80$, when using the P-gp model drug Rhodamine 123 and diffusion chambers with excised rat intestinal mucosa (43). Various other studies further demonstrate the efficacy of polysorbates to inhibit efflux pumps (44-46).

\section{POE Stearates (Myrj $\left.{ }^{\circledR}\right)$ and Alkyl-PEO Surfactants (Brij $\left.{ }^{\circledR}\right)$}

Some studies support the theory that POE stearates (commonly known as Myrj ${ }^{\circledR}$ ) and alkyl-PEO surfactants (commonly known as Brij ${ }^{\circledR}$ ) can inhibit efflux pumps. The oral bioavailability of the P-gp substrate cyclosporine A administered in a solid dispersion of polyoxyethylene 40 stearate (Myrj ${ }^{\circledR}$ 52) was in the same range as the oral bioavailability of the commercial product Sandimmune Neoral (47). If this effect was mediated only by drug solubilisation or by efflux pump inhibition was not investigated in the study. Lo demonstrated an improved intercellular accumulation of epirubicin in the presence of polyoxyethylene 40 stearate using Caco-2 cells. Moreover, the apical to basolateral transport of epirubicin through Caco- 2 cell layers increased in presence of polyoxyethylene 40 stearate, whereas the basolateral to apical transport decreased. These results indicate polyoxyethylene 40 stearate mediated efflux pump inhibition (44). Similar results were gained when using polyoxyethylene laurylether (Brij $\left.{ }^{\circledR} 30\right)$. In another study, conducted by Föger et al., tablets based on polyoxyethylene 40 stearate containing the $\mathrm{P}$-gp substrate rhodamine 123 increased the oral bioavailability in rats about 2.4-fold (48). The results of this study, showing also the effect of other polymeric efflux pump inhibitors are shown in Fig. 5.

\section{Poloxamers}

Poloxamers are widely known under the brand name Pluronics $\AA$. Pluronic $\AA$ block copolymers consist of ethylene oxide (EO) and propylene oxide (PO) segments arranged in the basic A-B-A structure (Fig. 6). Therefore, Pluronics ${ }^{\circledR}$ are amphiphilic copolymers whose size and hydrophilicity/lipophilicity can be varied by using different chain lengths of EO and PO. Pluronics ${ }^{\circledR}$ are so called "functional excipients," which can affect immune response and wound healing (49, 50). A modulation of MDR related processes mediated by Pluronics ${ }^{\circledR}$ has been demonstrated the first time more than 10 years ago (32). Pluronic ${ }^{\circledR}$ P85, which has been studied extensively in terms of efflux pump inhibition, has a molecular mass of about 4,600 Da. The efflux pump inhibitory activity of Pluronics ${ }^{\circledR}$ is used in two main areas: (1) blood brain barrier (BBB) drug delivery and (2) cancer therapy. The efflux pump inhibitory mechanism is believed to be due to (a) Pluronic $\AA$ mediated ATPase inhibition and ATP depletion and (b) effects of Pluronics ${ }^{\circledR}$ on membrane fluidization (51). It has been proven that the effect of Pluronics ${ }^{\circledR}$ on energy conservation is mediated by single chain units (unimers). Experiments revealed that the inhibitory effect decreases when reaching the critical micelle concentration (52). Regarding membrane fluidization, a change in the membrane microviscosity using a hydrophobic membrane probe was observed (51). Apart from Pluronics ${ }^{\circledR}$, another copolymer, CRL-1605 has already been used to

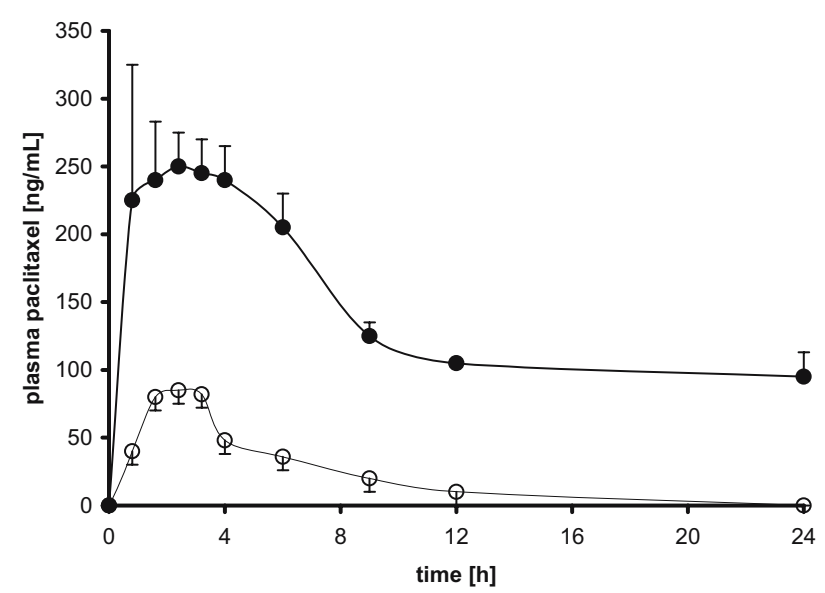

Fig. 4. Plasma curves of paclitaxel $(\mathrm{ng} / \mathrm{ml})$ in rats after oral administration of $25 \mathrm{mg} / \mathrm{kg}$ paclitaxel (open circle) and in combination with $50 \mathrm{mg} / \mathrm{kg}$ TPGS 1000 (filled circle). Figure adapted from (18) 


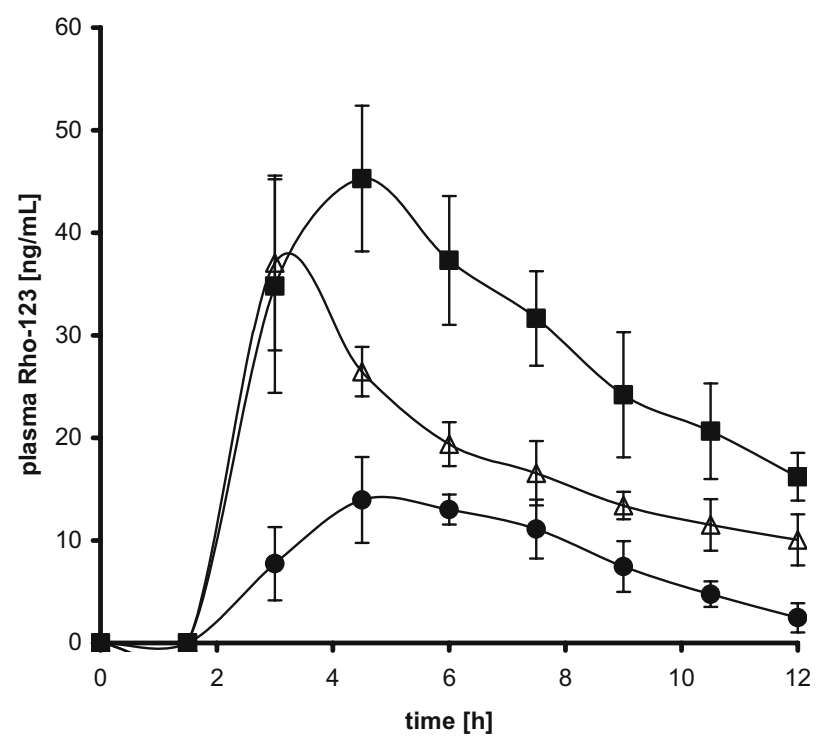

Fig. 5. Plasma curves of Rho- $123(\mathrm{ng} / \mathrm{ml})$ in rats after oral administration of $1.5 \mathrm{mg}$ Rhodamine 123 in Pluronic ${ }^{\circledR}$ P85 tablets (filled circle), Myrj ${ }^{\circledR} 52$ tablets (triangle) and chito-TBA/GSH tablets (filled square). Figure adapted from (48)

successfully improve the oral uptake of tobramycin and amikacin via P-gp inhibition $(24,53)$.

\section{Poloxamers for BBB Delivery}

An excellent review article focussing on the role of Pluronics ${ }^{\circledR}$ in the delivery of efflux pump substrates through the $\mathrm{BBB}$ as well as discussing the mechanisms of Pluronic ${ }^{\circledR}$ mediated efflux pump inhibition has been published among others by the pioneers in the field of Pluronic ${ }^{\circledR}$ efflux pump interactions, Kabanov et al. (54). The first study focussing on the efflux pump modulating effect of Pluronics ${ }^{\circledR}$ in the BBB was published by Miller et al. (52). In this study, a concentration dependent inhibitory activity of Pluronic ${ }^{\circledR}$ P85 was observed by monitoring the accumulation of rhodamine 123 in brain microvessel endothelial cell (BMVEC) monolayers. Nowadays, a multitude of data demonstrating the efficacy of Pluronics ${ }^{\circledR}$ for $\mathrm{BBB}$ delivery is available. In vitro permeation studies using bovine brain microvessel endothelial cells (BBMEC) and a broad variety of efflux pump substrates including e.g., etoposide, doxorubicin and paclitaxel showed an improved apical to basolateral drug transport (55). In Table I, the permeation enhancement ratios of various efflux pump substrates in the presence of Pluronic ${ }^{\circledR}$ P85 using BBMEC monolayers are summarized. Moreover, data that demonstrate the in vivo efficacy of Pluronics ${ }^{\circledR}$ to improve $\mathrm{BBB}$ transport of efflux pump substrates are available. In one study, the brain accumulation of digoxin in wild type mice, mdr1a knockout mice and wild type mice treated with Pluronic ${ }^{\circledR}$ P85 was investigated. It could be demonstrated that Pluronic ${ }^{\circledR}$ P85 prolonged the residence time and increased the concentration of digoxin in the brain (26).

\section{Poloxamers in Cancer Therapy}

The role of Pluronics ${ }^{\circledR}$ in cancer therapy has been comprehensively reviewed (56). Generally, polymeric exci- pients have been used in cancer therapy to overcome MDR by two different approaches: either by circumventing efflux pump transport or by inhibiting efflux transporter proteins. Kopecek et al. demonstrated that doxorubicin-HPMA [ $N$-(2hydroxypropyl)methacrylamide] conjugate is transported via a different mechanism than the free drug. The conjugate is most likely transported in the cells via endocytosis, which represents a P-gp independet pathway, whereas the free drug is transported via membrane diffusion, a pathway which is affected by efflux pumps $(57,58)$.

Pluronic $\AA$ formulated doxorubicin has been evaluated to be efficient in vivo in the treatment of various different kinds of cancer (59). One mechanism, which is responsible for the enhanced cytotoxicty of anticancer agents in the presence of Pluronics ${ }^{\circledR}$, is P-gp inhibition. It has been demonstrated in vitro that there is an enhanced doxorubicin accumulation in P-gp expressing cells in the presence of Pluronics ${ }^{\circledR}$. Contrary, this effect could not be observed when using non P-gp expressing cell lines $(60,61)$. These findings could be further supported by studies of Evers et al. and Batrakova et al. who showed that the accumulation and permeation of various P-gp substrates was enhanced in the presence of Pluronics ${ }^{\circledR}$ when using MDR1 transfected cells, whereas no or only little effects could be observed in non-transfected cells $(26,62)$. Also no enhanced accumulation of non-P-gp substrates in neither resistant nor sensitive cells could be observed (26,52, 63). Moreover there is evidence that Pluronics ${ }^{\circledR}$ can inhibit other efflux pumps such as MRP1 and MRP2. However, the effect of Pluronics ${ }^{\circledR}$ on P-gp ATPase activity is considerably greater compared with the effects on MRP1 and MRP2 ATPases (64). This hypothesis is supported by the data presented in Table I. Generally, the enhancement ratio of P-gp substrates or $\mathrm{P}$-gp/MRP substrates tends to be higher in comparison to the enhancement ratio of MRP substrates. Besides efflux pump inhibition, Pluronics ${ }^{\circledR}$ are promising agents in cancer therapy because they affect drug sequestration and the GSH/GST detoxification system. The importance of these mechanisms and the beneficial effect of Pluronics ${ }^{\circledR}$ on them have been summarized previously (56).

\section{Dendrimers}

Dendrimers (dendritic polymers) are fully synthetic macromolecules with a defined structure. From a core located in the center of the dendrimer, branched repeat units emanate. The surface can display functional groups such as primary amines or hydroxyl groups. Exemplarily, the structure of a polyamidoamine (PAMAM) dendrimer is shown in Fig. 7. The first dendrimers have been described nearly 30 years ago (65). Dendrimers are used as delivery systems for potent anticancer drugs (66), in gene delivery and in imaging $(67,68)$. There is some evidence that dendrimers might be interesting tools for the delivery of efflux pumps substrates. D'Emanuele et al. showed that the conjugation of the P-gp substrate propranolol to generation 3 (G3) and lauroyl-G3<smiles>CC(CCCCOCCCO)OCCCC(C)(C)OCCO</smiles>

Fig. 6. Chemical structures of poloxamers (Pluronics ${ }^{\circledR}$ ) 
Table I. Effect of Pluronic ${ }^{\circledR}$ P85 on the Permeability of Various Efflux Pump Substrates Through Brain Microvessel Endothelial Cell (BMVEC) Monolayers

\begin{tabular}{llc}
\hline Efflux Pump Substrate & Efflux Pump & $\begin{array}{l}\text { Enhancement } \\
\text { Ratio }\end{array}$ \\
\hline Methotrexate & MRP & 1.3 \\
Fluorescein & MRP & 1.5 \\
Rhodamine 123 & P-gp & 1.6 \\
Zidovudin & MRP & 2.0 \\
Doxorubicin & P-gp, MRP & 2.4 \\
Digoxin & P-gp & 4.1 \\
Ritonavir & P-gp & 7.7 \\
Paclitaxel & P-gp & 11.2 \\
Vinblastin & P-gp, MRP & 19.0 \\
\hline
\end{tabular}

Enhancement ratio=apical to basolateral substrate transport in the presence of P85/apical to basolateral substrate transport in buffer; table adapted from (54).
PAMAM dendrimers improved apical to basolateral transport and decreased basolateral to apical transport through Caco-2 monolayers. The mechanism responsible for this behaviour was attributed to a circumvention of P-gp transport rather than to $\mathrm{P}$-gp inhibition, because in the presence of the well known P-gp inhibitor cyclosporine A, no further improvement of propranolol transport was observed (69). However, it has been shown that the transport of efflux pump substrates in the presence of dendrimers was improved without conjugating the substrate to the dendrimer. The accumulation of vinblastine and doxorubicin using gut sacs was improved about three- and fourfold in the presence of a G3 dendrimer. These results might indicate a possible efflux pump inhibition (35).

\section{Thiomers}

Thiolated polymers, or so called "thiomers" have been recently introduced in the pharmaceutical arena. Thiomers are multifunctional polymers used in buccal, nasal, ocular, oral and vaginal delivery. It has been demonstrated that the introduction of thiol groups on polymers can lead to<smiles>NCCNC(=O)CCN(CCNC(=O)CCN(CCNC(=O)CCN(CCC(=O)NCCN(CCC(=O)NCCN(CCC(=O)NCCN)CCC(=O)NCCN)CCC(=O)NCCN(CCC(=O)NCCN)CCC(=O)NCCN)CCN(CCNC(=O)CCN(CCC(=O)NCCN(CCC(=O)NCCN)CCC(=O)NCCN)CCC(=O)NCCN(CCC(=O)NCCN)CCC(=O)NCCN)CCC(=O)NCCN(CCC(=O)NCCN)CCC(=O)NCCN)CCC(=O)NCCN(CCC(=O)NCCN)CCC(=O)NCCN)CCC(=O)NCCN</smiles>

Fig. 7. Chemical structure of a polyamidoamine (PAMAM) dendrimer 
improved mucadhesive, cohesive, enzyme inhibitory and permeation enhancing properties (70). The chemical structure of two widely used thiomers is provided in Fig. 8. Recently, it has been demonstrated that thiomers can inhibit efflux pumps (71). No data regarding the efflux pump inhibitory activity of unmodified chitosan, which often serves as polymeric backbone of thiomers, could be found. Also for unmodified polyacrylates, which represent another group of polymeric backbones used for thiomer synthesis, no data demonstrating an eventual efflux pump inhibitory effect is available. The use of carbopol, a crosslinked poly(acrylic)acid derivative-which is known to enhance the paracellular uptake of hydrophilic drugs via an opening of tight junctions mediated by calcium complexation (72-74) - did not lead to a pronounced improved cell accumulation of the efflux pump substrate doxorubicin in flow cytometry studies (enhancement factor $1.15 \pm 0.04$ ) (75). Therefore, it is most likely that the efflux pump inhibitory activity of thiomers is mediated by the introduced thiol groups.

In studies with the P-gp substrate Rhodamine 123 it has been demonstrated that the thiomer chitosan-thiobutylamidine (chito-TBA) improves apical to basolateral substrate transport through excised guinea pig ileal mucosa and furthermore decreases basolateral to apical substrate transport. This effect was even more pronounced when using a combination of chito-TBA and glutathione (GSH) (71). Föger et al. showed that oral administration of tablets containing a combination of chito-TBA and GSH led to significantly improved Rhodamine 123 plasma levels in rats in comparison to tablets based on either poloxamer or Myrj ${ }^{\circledR}$ $(48,76)$. The results are shown in Fig. 5. An improved uptake

$\mathbf{a}$

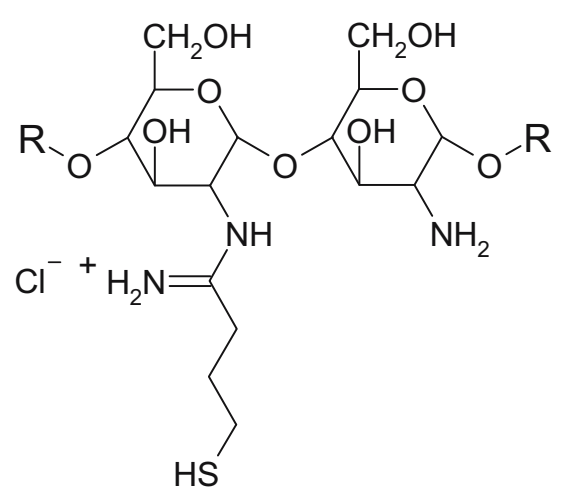

b<smiles>[R]C(CC(CC([R])C(=O)[O-])C(=O)NC(CS)C(=O)[O-])C(=O)[O-]</smiles>

Fig. 8. Structure of thiomers: a chitosan-thiobutylamidine (chitoTBA), b poly(acrylic acid)-cysteine (PAA-Cys) of the efflux pump substrate, saquinavir, in presence of a thiomer/GSH system has also already been demonstrated (77). Studies demonstrating an improved uptake of paclitaxel after oral administration in a thiomer delivery system are currently under review. Moreover, it has been demonstrated that the transepithelial transport of sulforhodamine 101, representing a MRP2 substrate, in the absorptive direction was improved up to about 4.5 -fold in presence of $0.5 \%(\mathrm{~m} / \mathrm{v})$ thiolated poly(acrylic acid) of various molecular mass (78). These findings seem to indicate that thiomers might be useful tools to deliver various drugs which are affected by efflux transporters such as P-gp and MRP.

\section{DISCUSSION}

Various polymeric agents are nowadays known to inhibit efflux pumps. They gained attention in different research fields, including cancer therapy and drug delivery. In Table II, efflux pump substrates that have been used so far in connection with polymeric efflux pump inhibitors are summarized. The classification regarding application is based on the used cell-lines (BBMEC monolayers, healthy intestinal tissue, Caco-2 monolayers and other cancer cell-lines) or animals (tumour bearing, healthy) and on the substrate (anticancer drug, other drug/ substrate). Efflux pumps substrates listed in the subdivision "cancer therapy" are anticancer drugs that have been used in studies using cancer cell-lines or tumour bearing animals.

Efflux pump inhibition can be mediated by numerous mechanisms. Especially SMIs are capable of inhibiting efflux pump by blocking or modifying efflux pump drug-binding sites (79). However, efflux pumps display various drugbinding sites, so that a targeted development of SMIs inhibitors remains difficult. There is controversy about the exact number and nature of efflux pump drug binding sites. Up to four distinct and partially overlapping drug-binding sites for P-gp have been identified so far (80-83). According to another hypothesis, P-gp has a "common drug-binding site," and the binding of structurally diverse substrates can be explained by a "substrate induced fit," in which the substrates create their own drug-binding sites within the area circled by the transmembrane domains (TMD) 4-6 and 9-12 (84,85). So far developed structure activity relation (SAR) models are either based on ligands or on homologue models, because high resolution $\mathrm{X}$-ray structures of the transporter proteins are not available yet (86-88). A target-oriented design of polymeric efflux pump inhibitors is even more challenging and intrinsic in comparison to the design of SMIs, because additional factors including unspecific interactions with the cell membrane might be responsible for efflux pump inhibition. In Fig. 9, the possible interactions of polymers and efflux pumps are schematically presented. The mechanism of polymeric inhibitors often seems to be mediated by altering the integrity of cell membrane lipids (Fig. 9b). This mechanism is most likely responsible for the inhibitory activity of PEG and of polymers that do not access the cells, like polysaccharides and thiomers. For thiomers, also a mechanism based on the formation of disulfide bonds between the free thiol groups of the thiomers and cysteine of P-gp inside of the transporter channel has been suggested (Fig. 9e). Especially an interaction of thiomers with the channel-forming transmembrane domains of P-gp has been 
Table II. Efflux Pump Substrates, Polymeric Efflux Pump Inhibitors and the According Application Thereof

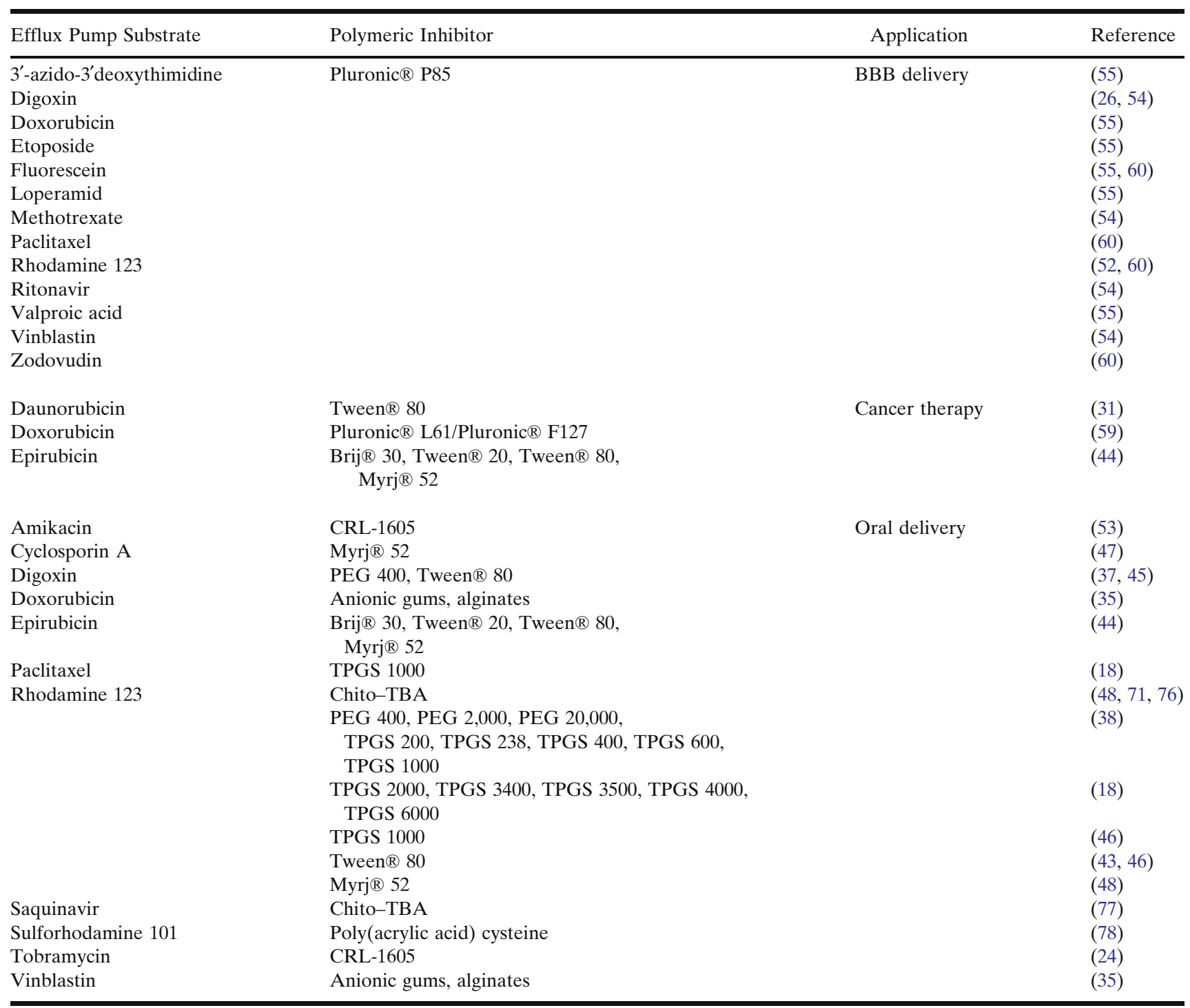

discussed (89), because two of the regions, namely 2 and 11, exhibit cysteine subunits on position 137 and 956. However, no experimental data backing up this theory is currently available. In contrast, for amphiphilic compounds such as poloxamers, there is experimental evidence that shows that membrane alterations are at least partly responsible for efflux pump inhibition. It has been demonstrated that membrane fluidization mediated by pluronics leads to a decrease of the ATPase activity (Fig. 9b) (51). Moreover, the poloxamer unimers inhibit efflux pumps also via intercellular interactions, especially by interfering with ATP related mechanisms such as ATP depletion (Fig. 9a) (51). Therefore, similar mechanisms as described for poloxamers might be responsible for other amphipilic compounds such as Myrj ${ }^{\circledR}$ and Brij ${ }^{\circledR}$. Interestingly, it was demonstrated recently by the research group of Lehr, that the efflux pump inhibitory activity of TPGS 1000 is not mediated by membrane fluidization. Membrane fluidization was observed at concentrations 100 -fold higher than necessary for P-gp inhibition. A modulation of the ATPase activity correlated with the inhibitory potential, which leads to the conclusion that ATPase inhibition is mainly responsible for the inhibitory activity of TPGS (Fig. 9d) (90). The inhibitory mechanism of dendrimers has not been evaluated so far. It has been demonstrated, that dendrimers are transported into the cells via endocytosis (91). Therefore, efflux pump inhibition mediated by ATP-depletion, ATPase inhibition or alteration of the cell membranes seem to be possible explanations. Due to the rigid structure of dendrimers, blocking of substrate binding-sites seems rather unlikely, although this possibility cannot be excluded. Moreover, it is not completely clear yet, if the effect of dendrimers regarding efflux pump substrate transport is really based on inhibitory mechanisms or on bypassing efflux transporters (Fig. 9c). It has been demonstrated by Kopecek et al., that drug-polymer conjugates can bypass P-gp mediated transport $(57,58)$. Especially regarding amphiphilic compounds, other possible mechanisms apart from efflux pump inhibition that can lead to an improved oral drug bioavailability or changes in pharmacokinetics must be taken into consideration. Most important in this context are permeation enhancing effects mediated by interactions with the cell membranes and drug solubilising effects of such compounds. 


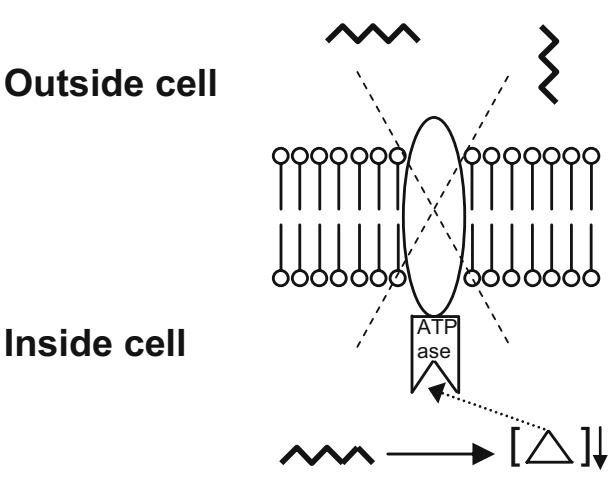

a

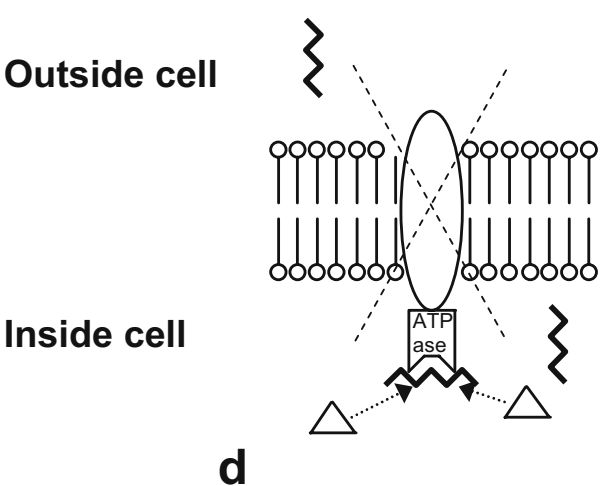

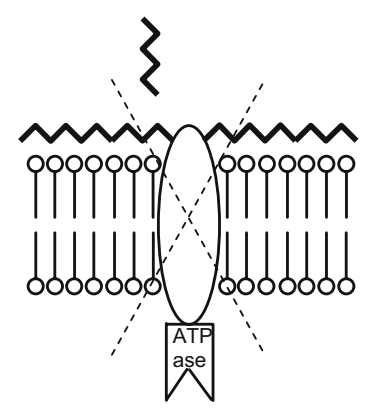

b

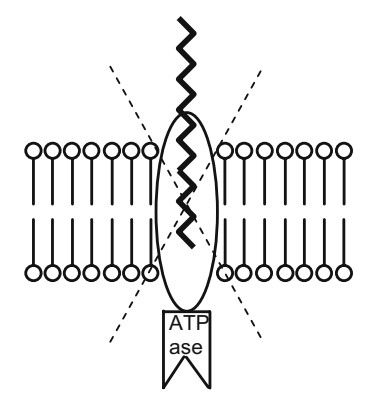

e

Fig. 9. Schematic presentation of interactions between polymeric efflux pump inhibitors and efflux pumps; polymer $(\wedge \wedge \wedge)$, ATP (triangle), drug (square); a inhibition mediated by ATP depletion, $\mathbf{b}$ inhibition mediated by interactions with the membrane, $\mathbf{c}$ bypassing drug efflux by a drug-polymer conjugate, $\mathbf{d}$ inhibition mediated by interfering with ATP-binding sites and e blocking of drug binding sites or other sites within the trans-membrane domains (TMB)

When choosing a polymeric efflux pump inhibitor for a certain application, several points have to be considered. One important factor is definitely the concentration of the auxiliary agent. In Table III, polymeric inhibitors, the celltype used for the investigations, the involved efflux pumps as well as the effective concentration/s are summarized. Con- centrations ranging from $0.001 \%$ [Pluronic ${ }^{\circledR}$ P85; (52)] up to $20 \%$ [PEGs; (38)] have been evaluated to be effective in vitro. In comparison to the mostly lipophilic and well absorbed SMIs (92), many orally administered polymeric auxiliary agents are not absorbed and therefore systemic mediated toxicity or side effects can be minimised or even

Table III. Polymeric Efflux Pump Inhibitors, Tested Cell Types, Inhibited Transporters and Effective Polymer Concentration

\begin{tabular}{|c|c|c|c|c|}
\hline Polymer & Cell Type & Transporter & Effective Concentration (\%) & Literature \\
\hline Xanthan gum & Rat intestine & P-gp & 0.05 & $(35)$ \\
\hline Gellan gum & Rat intestine & P-gp & 0.05 & $(35)$ \\
\hline Flavicam & Rat intestine & P-gp & 0.05 & $(35)$ \\
\hline Ascophyllum & Rat intestine & P-gp & 0.05 & (35) \\
\hline Dextran & Rat intestine & P-gp & $0.05-0.1$ & (35) \\
\hline PEG 300 & Caco-2, MDCK-MDR1 & P-gp & 20 & $(39,40)$ \\
\hline PEG 400, 2,000, 20,000 & Rat intestine & P-gp & $0.1-20$ & $(37,38)$ \\
\hline TPGS 1000 & Caco-2 & P-gp & 0.0038 & (46) \\
\hline TPGS 200-6000 & Сaco-2 & P-gp & 0.005 & $(42)$ \\
\hline Tween 80 & $\begin{array}{l}\text { Ehrlich ascites tumor cells, } \\
\text { rat intestine, Caco-2 }\end{array}$ & P-gp, MRP1 & $<0.13$ & $(31,46)$ \\
\hline Myrj 52 & Rat intestine & P-gp & 0.5 & $(48)$ \\
\hline Pluronic P85 & BBMEC & P-gp, MRP & $0.001-1$ & $(52,55)$ \\
\hline PAMAM G3, G3.5 dendrimer & Rat intestine & P-gp & 0.05 & $(35)$ \\
\hline Chito-TBA & $\begin{array}{l}\text { Guinea pig intestine, rat intestine, } \\
\text { Caco-2 }\end{array}$ & P-gp & $0.25-0.5$ & $(71,76,77)$ \\
\hline $\begin{array}{l}\text { PAA-Cys (PAA 2, 100, 250, 450, } \\
3000 \mathrm{kDa})\end{array}$ & Rat intestine & MRP2 & 0.5 & (78) \\
\hline
\end{tabular}


excluded $(93,94)$. This renders polymeric efflux pump inhibitors an interesting tool for oral drug delivery. Representatives of this group of polymeric inhibitors are polysaccharides as well as thiomers. Another advantage of such high molecular mass inhibitors is that the drug can be embedded in the polymeric matrix. A controlled release allows that the drug is liberated at the same intestinal tissues as the efflux pump inhibition takes place. However, SMIs might be the better option when further systemic efflux pump inhibition is intended. Due to the absorption of SMIs, systemic inhibitory effects might e.g., facilitate additionally improved BBB delivery. Dendrimers and Pluronics ${ }^{\circledR}$ have so far not gained too much attention for oral drug delivery, however, they might be promising candidates too. Regarding BBB delivery and cancer therapy, most studies have been conducted with block copolymers. The big advantage of such polymers in comparison to other polymers discussed in the current review is that there is much data available that proofs their safety. RheothRx, a clinical form of Pluronic ${ }^{\circledR}$ F68 for the treatment of myocardial infarction was well tolerated in human trials at cumulative doses as high as $2.2 \mathrm{~g} / \mathrm{kg}$ infused over $24 \mathrm{~h}$ (95). Although the formulation was withdrawn from phase III trials because of toxic concerns, it must be mentioned that the toxicity was rather mediated by impurities than by the poloxamer itself (96). Other studies conducted in rodents and non-rodents showed, that the toxic dose was about $1.0-1.3 \mathrm{~g} / \mathrm{kg}$, which is about 30 times higher than the concentration intended for a use in human volunteers $(97,98)$.

\section{CONCLUSION}

Up to date, the potential of various structural diverse polymeric compounds to inhibit efflux pumps has been demonstrated. In addition, their efficacy in cancer therapy as well as drug delivery could be shown. Especially the use of poloxamers in cancer therapy and BBB delivery is very promising and sufficient data-also of clinical trials-are available. Another emerging research field is the use of polymeric efflux pump inhibitors in oral drug delivery. There are various mechanisms that can be responsible for polymeric efflux pump inhibition, including membrane fluidization, ATP depletion and interaction with drug- or ATP-binding sites. For some polymers such as dendrimers, the mechanism/s still remain/s unclear. A better understanding of the interaction between efflux pumps and polymeric inhibitors would highly contribute to the development of more specific and safe inhibitors.

\section{REFERENCES}

1. R. L. Juliano and V. Ling. A surface glycoprotein modulating drug permeability in Chinese hamster ovary cell mutants. Biochim. Biophys. Acta 455:152-162 (1976).

2. F. Thiebaut, T. Tsuruo, H. Hamada, M. M. Gottesman, I. Pastan, and M. C. Willingham. Cellular localization of the multidrug-resistance gene product P-glycoprotein in normal human tissues. Proc. Natl. Acad. Sci. U. S. A. 84:7735-7738 (1987).

3. C. Cordon-Cardo, J. P. O'Brien, J. Boccia, D. Casals, J. R. Bertino, and M. R. Melamed. Expression of the multidrug resistance gene product (P-glycoprotein) in human normal and tumor tissues. J. Histochem. Cytochem. 38:1277-1287 (1990).

4. F. Girardin. Membrane transporter proteins: a challenge for CNS drug development. Dialogues Clin. Neurosci. 8:311-321 (2006).
5. S. Majumdar, S. Duvvuri, and A. K. Mitra. Membrane transporter/receptor-targeted prodrug design: strategies for human and veterinary drug development. Adv. Drug Deliv. Rev. 56:1437-1452 (2004).

6. M. V. Varma, O. P. Perumal, and R. Panchagnula. Functional role of P-glycoprotein in limiting peroral drug absorption: optimizing drug delivery. Curr. Opin. Chem. Biol. 10:367-373 (2006).

7. A. Tsuji. P-glycoprotein-mediated efflux transport of anticancer drugs at the blood-brain barrier. Ther. Drug Monit. 20:588-590 (1998).

8. H. Goldberg, V. Ling, P. Y. Wong, and K. Skorecki. Reduced cyclosporin accumulation in multidrug-resistant cells. Biochem. Biophys. Res. Commun. 152:552-558 (1988).

9. C. P. Yang, S. G. DePinho, L. M. Greenberger, R. J. Arceci, and S. B. Horwitz. Progesterone interacts with P-glycoprotein in multidrug-resistant cells and in the endometrium of gravid uterus. J. Biol. Chem. 264:782-788 (1989).

10. K. Yusa and T. Tsuruo. Reversal mechanism of multidrug resistance by verapamil: direct binding of verapamil to $\mathrm{P}$ glycoprotein on specific sites and transport of verapamil outward across the plasma membrane of K562/ADM cells. Cancer Res. 49:5002-5006 (1989)

11. J. Karlsson, S. M. Kuo, J. Ziemniak, and P. Artursson. Transport of celiprolol across human intestinal epithelial (Caco-2) cells: mediation of secretion by multiple transporters including $\mathrm{P}$ glycoprotein. Br. J. Pharmacol. 110:1009-1016 (1993).

12. I. A. de Lannoy and M. Silverman. The MDR1 gene product, Pglycoprotein, mediates the transport of the cardiac glycoside, digoxin. Biochem. Biophys. Res. Commun. 189:551-557 (1992).

13. D. Leveque and F. Jehl. P-glycoprotein and pharmacokinetics. Anticancer Res. 15:331-336 (1995).

14. S. Choudhuri and C. D. Klaassen. Structure, function, expression, genomic organization, and single nucleotide polymorphisms of human ABCB1 (MDR1), ABCC (MRP), and ABCG2 (BCRP) efflux transporters. Int. J. Toxicol. 25:231-259 (2006).

15. M. Mazel, P. Clair, C. Rousselle, P. Vidal, J. M. Scherrmann, D. Mathieu, and J. Temsamani. Doxorubicin-peptide conjugates overcome multidrug resistance. Anticancer Drugs 12:107-116 (2001).

16. T. J. Raub. P-glycoprotein recognition of substrates and circumvention through rational drug design. Mol. Pharmacol. 3:3-25 (2006).

17. M. V. Varma, Y. Ashokraj, C. S. Dey, and R. Panchagnula. Pglycoprotein inhibitors and their screening: a perspective from bioavailability enhancement. Pharmacol. Res. 48:347-359 (2003).

18. M. V. Varma and R. Panchagnula. Enhanced oral paclitaxel absorption with vitamin E-TPGS: effect on solubility and permeability in vitro, in situ and in vivo. Eur. J. Pharm. Sci. 25:445-453 (2005).

19. B. J. Aungst. Intestinal permeation enhancers. J. Pharm. Sci. 89:429-442 (2000).

20. A. Bernkop-Schnürch. The use of inhibitory agents to overcome the enzymatic barrier to perorally administered therapeutic peptides and proteins. J. Control. Release 52:1-16 (1998).

21. H. L. Luessen, C. O. Rentel, A. F. Kotzé, C.-M. Lehr, A. G. deBoer, J. C. Verhoef, and H. E. Junginger. Mucoadhesive polymers in peroral peptide drug delivery. IV. Polycarbophil and chitosan are potent enhancers of peptide transport across intestinal mucosae in vitro. J. Control. Release 45:15-23 (1997).

22. S. A. Galindo-Rodriguez, E. Allemann, H. Fessi, and E. Doelker. Polymeric nanoparticles for oral delivery of drugs and vaccines: a critical evaluation of in vivo studies. Crit. Rev. Ther. Drug Carr. Syst. 22:419-464 (2005).

23. J. S. Woo, C. H. Lee, C. K. Shim, and S. J. Hwang. Enhanced oral bioavailability of paclitaxel by coadministration of the Pglycoprotein inhibitor KR30031. Pharmacol. Res. 20:24-30 (2003).

24. S. K. Banerjee, C. Jagannath, R. L. Hunter, and A. Dasgupta. Bioavailability of tobramycin after oral delivery in FVB mice using CRL-1605 copolymer, an inhibitor of P-glycoprotein. Life Sci. 67:2011-2016 (2000).

25. W. M. Pardridge. Introduction to the Blood-Brain Barrier. Methodology, Biology and Pathology, Cambridge University Press, Cambridge, 1998. 
26. E. V. Batrakova, D. W. Miller, S. Li, V. Alakhov, A. V. Kabanov, and W. F. Elmquist. Pluronic P85 enhances the delivery of digoxin to the brain: in vitro and in vivo studies. $J$. Pharmacol. Exp. Ther. 296:551-557 (2001).

27. W. T. Beck, M. C. Cirtain, C. J. Glover, R. L. Felsted, and A. R. Safa. Effects of indole alkaloids on multidrug resistance and labeling of P-glycoprotein by a photoaffinity analog of vinblastine. Biochem. Biophys. Res. Commun. 153:959-966 (1988).

28. T. Tsuruo, H. Iida, S. Tsukagoshi, and Y. Sakurai. Overcoming of vincristine resistance in P388 leukemia in vivo and in vitro through enhanced cytotoxicity of vincristine and vinblastine by verapamil. Cancer Res. 41:1967-1972 (1981).

29. J. van Asperen, O. van Tellingen, A. Sparreboom, A. H. Schinkel, P. Borst, W. J. Nooijen, and J. H. Beijnen. Enhanced oral bioavailability of paclitaxel in mice treated with the Pglycoprotein blocker SDZ PSC 833. Br. J. Cancer 76:1181-1183 (1997).

30. H. A. Bardelmeijer, J. H. Beijnen, K. R. Brouwer, H. Rosing, W. J. Nooijen, J. H. Schellens, and O. van Tellingen. Increased oral bioavailability of paclitaxel by GF120918 in mice through selective modulation of P-glycoprotein. Clin. Cancer Res. 6:4416-4421 (2000).

31. E. Friche, P. B. Jensen, M. Sehested, E. J. Demant, and N. N. Nissen. The solvents cremophor EL and Tween 80 modulate daunorubicin resistance in the multidrug resistant Ehrlich ascites tumor. Cancer Commun. 2:297-303 (1990).

32. V. Alakhov, E. Y. Moskaleva, E. V. Batrakova, and A. V. Kabanov. Hypersensitization of multidrug resistant human ovarian carcinoma cells by pluronic P85 block copolymer. Bioconjug. Chem. 7:209-216 (1996).

33. J. Jodoin, M. Demeule, and R. Beliveau. Inhibition of the multidrug resistance P-glycoprotein activity by green tea polyphenols. Biochim. Biophys. Acta 1542:149-159 (2002).

34. Y. Honda, F. Ushigome, N. Koyabu, S. Morimoto, Y. Shoyama, T. Uchiumi, M. Kuwano, H. Ohtani, and Y. Sawada. Effects of grapefruit juice and orange juice components on P-glycoprotein- and MRP2-mediated drug efflux. Br. J. Pharmacol. 143:856-864 (2004).

35. B. Carreno-Gomez and R. Duncan. Compositions with enhanced oral bioavailability. USP 20030211072 (2002).

36. A. Bernkop-Schnürch, M. Hornof, and T. Zoidl. Thiolated polymers-thiomers: synthesis and in vitro evaluation of chitosan-2-iminothiolane conjugates. Int. J. Pharm. 260:229-237 (2003)

37. B. M. Johnson, W. N. Charman, and C. J. H. Porter. An in vitro examination of the impact of polyehtylene glycol 400, pluronic $\mathrm{P}$ 85 and vitamin E D-a-tocopheryl polyethylene glycol 1000 succinate on p-glycoprotein efflux and enterocyte-based metabolism in excised rat intestine. AAPS PharmSci. 4(4) (2002).

38. Q. Shen, Y. Lin, T. Handa, M. Doi, M. Sugie, K. Wakayama, N. Okada, T. Fujita, and A. Yamamoto. Modulation of intestinal Pglycoprotein function by polyethylene glycols and their derivatives by in vitro transport and in situ absorption studies. Int. J. Pharm. 313:49-56 (2006).

39. E. D. Hugger, K. L. Audus, and R. T. Borchardt. Effects of poly(ethylene glycol) on efflux transporter activity in Caco-2 cell monolayers. J. Pharm. Sci. 91:1980-1990 (2002).

40. E. D. Hugger, B. L. Novak, P. S. Burton, K. L. Audus, and R. T. Borchardt. A comparison of commonly used polyethoxylated pharmaceutical excipients on their ability to inhibit P-glycoprotein activity in vitro. J. Pharm. Sci. 91:1991-2002 (2002).

41. J. S. Choi and B. W. Jo. Enhanced paclitaxel bioavailability after oral administration of pegylated paclitaxel prodrug for oral delivery in rats. Int. J. Pharm. 280:221-722 (2004).

42. E. M. Collnot, C. Baldes, M. F. Wempe, J. Hyatt, L. Navarro, K. J. Edgar, U. F. Schaefer, and C.-M. Lehr. Influence of vitamin E TPGS poly(ethlyene glycol) chain length on apical efflux transporters in Caco-2 cell monolayers. J. Control. Release 111:35-40 (2006).

43. Y. Shono, H. Nishihara, Y. Matsuda, S. Furukawa, N. Okada, T. Fujita, and A. Yamamoto. Modulation of intestinal Pglycoprotein function by cremophor EL and other surfactants by an in vitro diffusion chamber method using the isolated rat intestinal membranes. J. Pharm. Sci. 93:877-885 (2004).

44. Y. L. Lo. Relationships between the hydrophilic-lipophilic balance values of pharmaceutical excipients and their multidrug resistance modulating effect in Caco-2 cells and rat intestines. $J$. Control. Release 90:37-48 (2003).

45. H. Zhang, M. Yao, R. A. Morrison, and S. Chong. Commonly used surfactant, Tween 80 , improves absorption of P-glycoprotein substrate, digoxin, in rats. Arch. Pharm. Res. 26:768-772 (2003).

46. B. D. Rege, J. P. Kao, and J. E. Polli. Effects of nonionic surfactants on membrane transporters in Caco-2 cell monolayers. Eur. J. Pharm. Sci. 16:237-246 (2002).

47. C. Liu, J. Wu, B. Shi, Y. Zhang, T. Gao, and Y. Pei. Enhancing the bioavailability of cyclosporine a using solid dispersion containing polyoxyethylene (40) stearate. Drug Dev. Ind. Pharm. 32:115-123 (2006).

48. F. Föger, H. Hoyer, K. Kafedjiiski, M. Thaurer, and A. BernkopSchnürch. In vivo comparison of various polymeric and low molecular mass inhibitors of intestinal P-glycoprotein. Biomaterials 27:5855-5860 (2006).

49. R. L. Hunter, J. McNicholl, and A. A. Lal. Mechanisms of action of nonionic block copolymer adjuvants. AIDS Res. Hum. Retrovir. 10:95-98 (1994).

50. G. Rodeheaver, V. Turnbull, M. T. Edgerton, L. Kurtz, and R. F. Edlich. Pharmacokinetics of a new skin wound cleanser. Am. J. Surg. 132:67-74 (1976).

51. E. V. Batrakova, S. Li, S. V. Vinogradov, V. Alakhov, D. W. Miller, and A. V. Kabanov. Mechanism of pluronic effect on pglycoprotein efflux system in blood brain barrier: contributions of energy depletion and membrane fluidization. Pharmacol. Exp. Ther. 299:483-493 (2001).

52. D. W. Miller, E. V. Batrakova, D. O. Waltner, V. Alakhov, and A. V. Kabanov. Interactions of pluronic block copolymers with brain microvessel endothelial cells: evidence for two potential pathways for drug absorption. Bioconjug. Chem. 8:649-657 (1997).

53. C. Jagannath, A. Wells, M. Mshvildadze, M. Olsen, E. Sepulveda, M. Emanuele, R. L. J. Hunter, and A. Dasgupta. Significantly improved oral uptake of amikacin in FVB mice in the presence of CRL-1605 copolymer. Life Sci. 64:1733-1738 (1999).

54. A. V. Kabanov, E. V. Batrakova, and D. W. Miller. Pluronic block copolymers as modulators of drug efflux transporter activity in the blood-brain barrier. Adv. Drug Deliv. Rev. 55(1):151-164 (2003).

55. E. V. Batrakova, S. Li, D. W. Miller, and A. V. Kabanov. Pluronic P85 increases permeability of a broad spectrum of drugs in polarized BBMEC and Caco-2 cell monolayers. Pharm. Res. 16:1366-1372 (1999).

56. A. V. Kabanov, E. V. Batrakova, and V. Y. Alakhov. Pluronic block copolymers for overcoming drug resistance in cancer. $A d v$. Drug Deliv. Rev. 54:759-779 (2002).

57. J. Kopecek, P. Kopeckova, T. Minko, and Z. Lu. HPMA copolymer-anticancer drug conjugates: design, activity, and mechanism of action. Eur. J. Pharm. Biopharm. 50:61-81 (2000).

58. J. Kopecek, P. Kopeckova, T. Minko, Z. R. Lu, and C. M. Peterson. Water soluble polymers in tumor targeted delivery. $J$. Control. Release 74:147-158 (2001).

59. V. Alakhov, E. Klinksi, S. Li, G. Pietrzynski, A. Venne, E. Batrakova, T. Bronitch, and A. V. Kabanov. Block copolymer based formulation of doxorubicin. From cell screen to clinical trials. Colloids Surf., B Biointerfaces 16:113-134 (1999).

60. A. Venne, S. Li, A. Mandeville, A. V. Kabanov, and V. Alakhov. Hypersensitizing effect of pluronic L61 on cytotoxic activity, transport, and subcellular distribution of doxorubicin in multiple drug-resistant cells. Cancer Res. 56(16):3626-3629 (1996).

61. E. Batrakova, S. Lee, S. Li, A. Venne, V. Alakhov, and A. V. Kabanov. Fundamental relationships between the composition of pluronic block copolymers and their hypersensitization effect in MDR cancer cells. Pharm. Res. 16:1373-1379 (1999).

62. R. Evers, M. Kool, A. J. Smith, L. van Deemter, M. de Haas, and P. Borst. Inhibitory effect of the reversal agents V-104, GF120918 and Pluronic L61 on MDR1 Pgp-, MRP1- and MRP2mediated transport. Br. J. Cancer 83:366-374 (2000).

63. E. V. Batrakova, H. Y. Han, V. Alakhov, D. W. Miller, and A. V. Kabanov. Effects of pluronic block copolymers on drug absorption in Caco-2 cell monolayers. Pharm. Res. 15:850-855 (1998).

64. E. V. Batrakova, S. Li, Y. Li, V. Y. Alakhov, and A. V. Kabanov. Effect of pluronic P85 on ATPase activity of drug efflux transporters. Pharm. Res. 21:2226-2233 (2004). 
65. E. Buhleier, W. Wehner, and F. Vögtle. "Cascade"- and "nonskid-chain-like" syntheses of molecular cavity topologies. Synthesis 2:155-158 (1978).

66. E. R. Gillies and J. M. Frechet. Dendrimers and dendritic polymers in drug delivery. Drug Discov. Today 10:35-43 (2005).

67. C. Dufes, I. F. Uchegbu, and A. G. Schatzlein. Dendrimers in gene delivery. Adv. Drug Deliv. Rev. 57:2177-2202 (2005).

68. V. J. Venditto, C. A. Regino, and M. W. Brechbiel. PAMAM dendrimer based macromolecules as improved contrast agents. Mol. Pharm. 2:302-311 (2005).

69. A. D'Emanuele, R. Jevprasesphant, J. Penny, and D. Attwood. The use of a dendrimer-propranolol prodrug to bypass efflux transporters and enhance oral bioavailability. J. Control. Release 95:447-453 (2004).

70. A. Bernkop-Schnürch. Thiomers: a new generation of mucoadhesive polymers. Adv. Drug Deliv. Rev. 57:1569-1582 (2004).

71. M. Werle and M. Hoffer. Glutathione and thiolated chitosan inhibit multidrug resistance P-glycoprotein activity in excised small intestine. J. Control. Release 111:41-46 (2006).

72. H. L. Luessen, C. O. Rentel, A. F. Kotzé, C.-M. Lehr, A. B. G. de Boer, J. C. Verhoef, and H. E. Junginger. Polycarbophil and chitosan are potent enhancers of peptide transport across intestinal mucosae in vitro. J. Control. Release 45(1):15-23 (1997).

73. L. Bromberg. Interactions among proteins and hydrophobically modified polyelectrolytes. J. Pharm. Pharmacol. 53:541-547 (2001).

74. H. L. Luessen, C.-M. Lehr, C.-O. Rentel, A. B. J. Noach, A. G. de Boer, J. C. Verhoef, and H. E. Junginger. Bioadhesive polymers for the peroral delivery of peptide drugs. J. Control. Release 29:329-338 (1994).

75. L. Bromberg and V. Alakhov. Effects of polyether-modified poly(acrylic acid) microgels on doxorubicin transport in human intestinal epithelial Caco-2 cell layers. J. Control. Release 88:11$22(2003)$.

76. F. Föger, T. Schmitz, and A. Bernkop-Schnürch. In vivo evaluation of an oral delivery system for P-gp substrates based on thiolated chitosan. Biomaterials 27:4250-4255 (2006).

77. F. Föger, K. Kafedjiiski, H. Hoyer, B. Loretz, and A. BernkopSchnürch. Enhanced transport of P-glycoprotein substrate saquinavir in presence of thiolated chitosan. J. Drug Target. 15:132-139 (2006).

78. V. Grabovac and A. Bernkop-Schnürch. Thiolated polymers as effective inhibitors of intestinal Mrp2 efflux pump transporters. Sci. Pharm. 74 (2006).

79. L. Jette, G. F. Murphy, and R. Beliveau. Drug binding to Pglycoprotein is inhibited in normal tissues following SDZ-PSC 833 treatment. Int. J. Cancer 76:729-737 (1998).

80. S. Dey, M. Ramachandra, I. Pastan, M. M. Gottesman, and S. V. Ambudkar. Evidence for two nonidentical drug-interaction sites in the human P-glycoprotein. Proc. Natl. Acad. Sci. U. S. A. 94:10594-10599 (1977).

81. C. Pascaud, M. Garrigos, and S. Orlowski. Multidrug resistance transporter P-glycoprotein has distinct but interacting binding sites for cytotoxic drugs and reversing agents. Biochem. J. 333:351-358 (1998).

82. A. B. Shapiro, K. Fox, P. Lam, and V. Ling. Stimulation of Pglycoprotein mediated drug transport by prazosin and progesterone. Evidence for a third drug-binding site. Eur. J. Biochem. 259(3):841-850 (1999).
83. M. R. Lugo and F. J. Sharom. Interaction of LDS-751 with Pglycoprotein and mapping of the location of the $\mathrm{R}$ drug binding site. Biochemisrtry 44:643-655 (2005).

84. T. W. Loo and D. M. Clarke. Location of the rhodamine-binding site in the human multidrug resistance P-glycoprotein. J. Biol. Chem. 277:44332-44338 (2002).

85. T. W. Loo, M. C. Bartlett, and D. M. Clarke. Substrate-induced conformational changes in the transmembrane segments of human P-glycoprotein. Direct evidence for the substrate-induced fit mechanism for drug binding. J. Biol. Chem. 278(16):13603-13606 (2003).

86. P. Crivori, B. Reinach, D. Pezzetta, and I. Poggesi. Computational models for identifying potential P-glycoprotein substrates and inhibitors. Mol. Pharm. 3:33-44 (2006).

87. R. A. Shilling, H. Venter, S. Velamakanni, A. Bapna, B. Woebking, S. Shahi, and H. W. van Veen. New light on multidrug binding by an ATP-binding-cassette transporter. Trends Pharmacol. Sci. 27:195-203 (2006).

88. S. Ekins, R. B. Kim, B. F. Leake, A. H. Dantzig, E. G. Schuetz, L. B. Lan, K. Yasuda, R. L. Shepard, M. A. Winter, J. D. Schuetz, J. H. Wikel, and S. A. Wrighton. Three-dimensional quantitative structure-activity relationships of inhibitors of $\mathrm{P}$ glycoprotein. Mol. Pharm. Pharmacol. 61:964-973 (2002).

89. A. Bernkop-Schnürch and V. Grabovac. Polymeric efflux pump inhibitors in oral drug delivery. Am. J. Drug Deliv. 4:263-272 (2006).

90. E. M. Collnot, C. Baldes, M. F. Wempe, R. Kappl, J. Huttermann, J. A. Hyatt, K. J. Edgar, U. F. Schaefer, and C. M. Lehr. Mechanism of inhibition of p-glycoprotein mediated efflux by vitamin e TPGS: influence on ATPase activity and membrane fluidity. Mol. Pharm. 4(3):465-474 (2007)

91. R. Jevprasesphant, J. Penny, D. Attwood, and A. D'Emanuele. Transport of dendrimer nanocarriers through epithelial cells via the transcellular route. J. Control. Release 97:259-267 (2004).

92. J. Ferte. Analysis of the tangled relationships between Pglycoprotein-mediated multidrug resistance and the lipid phase of the cell membrane. Eur. J. Biochem. 267:277-294 (2000).

93. Y. Takehisa, S. Takaharu, T. Eiji, and N. Osamu. Disposition of polycarbophil calcium (HSR-237) in rats and dogs. Iyakuhin Kenkyu 28:23-32 (1997).

94. S. Muranishi. Absorption enhancers. Crit. Rev. Ther. Drug Carr. Syst. 7:1-33 (1990).

95. G. L. Schaer, L. J. Spaccavento, K. F. Browne, K. A. Krueger, D. Krichbaum, J. M. Phelan, W. O. Fletcher, C. L. Grines, S. Edwards, M. K. Jolly, and R. J. Gibbons. Beneficial effects of RheothRx injection in patients receiving thrombolytic therapy for acute myocardial infarction. Results of a randomized, doubleblind, placebo-controlled trial. Circulation 94:298-307 (1996).

96. K. Toth, L. Bogar, I. Juricskay, M. Keltai, S. Yusuf, L. J. Haywood, and H. J. Meiselman. The effect of RheothRx Injection on the hemorheological parameters in patients with acute myocardial infarction. Clin. Hemorheol. Microcirc. 17:117-125 (1997).

97. V. Alakhov, E. Klinksi, S. Li, G. Pietrzynski, A. Venne, E. Batrakova, T. Bronitch, and A. V. Kabanov. Block copolymerbased formulation of doxorubicin. From cell screen to clinical trials. Colloids Surf., B Biointerfaces 16:113-134 (1999).

98. J. M. Blonder, L. Baird, J. C. Fulfs, and G. J. Rosenthal. Dosedependent hyperlipidemia in rabbits following administration of poloxamer 407 gel. Life Sci. 65:261-266 (1999). 